This is a draft of a chapter that has been accepted for publication by Oxford University Press in the forthcoming book Oxford Handbook of Acceptance and Commitment Therapy edited by Michael P. Twohig, Michael E. Levin, \& Julie M. Petersen due for publication in 2021-2022. This chapter was finished in December of 2020.

\title{
Cognitive defusion
}

\section{Francisco J. Ruiz, Bárbara Gil-Luciano, \& Miguel A. Segura-Vargas}

\begin{abstract}
This chapter reviews the conceptualization and empirical evidence of the midlevel process called cognitive defusion. Firstly, we present examples of cognitive fusion and cognitive defusion definitions offered in acceptance and commitment therapy (ACT) manuals, discuss their relationships with other ACT midlevel processes, and offer a relational frame theory (RFT) conceptualization of these processes. Secondly, we describe the type of cognitive defusion exercises and discuss the basic processes involved in them. Thirdly, we review the measurement of cognitive (de)fusion in the form of self-report instruments, behavioral measures, and the assessment in the clinical session. Fourthly, we present a review of the research on cognitive (de)fusion separated in laboratory research, survey research, and the analysis of processes of change in clinical trials. Lastly, we discuss some challenges and future directions in conceptualizing and researching cognitive (de)fusion.
\end{abstract}

Key words: Cognitive defusion; Acceptance and commitment therapy; Relational frame theory; Contextual behavioral science; Self-as-context; Psychological flexibility.

Midlevel functional terms are higher-level functional abstractions that serve as shortcuts for applying basic principles to complex applied settings (Vilardaga, Hayes, Levin, \& Muto, 2009). Acceptance and commitment therapy (ACT; Hayes, Strosahl, \& Wilson, 1999; Wilson \& Luciano, 2002) is usually presented in midlevel terms, with cognitive fusion and cognitive defusion being some of the most original and older concepts. This chapter will provide a conceptual overview of them and the accompanying research. First, we will define these constructs as usually presented in ACT, present the interrelationship with other midlevel ACT processes, and provide a relational frame theory (RFT) conceptualization. Second, we will describe examples of clinical work with cognitive defusion and analyze some of the key processes involved. Third, we will describe the instruments developed for measuring cognitive (de)fusion. Fourth, we will review the empirical evidence regarding the efficacy of cognitive defusion exercises, component studies, survey research, and its role as a process of change in clinical interventions. Lastly, we will suggest challenges and future research directions.

\section{A conceptual overview of cognitive defusion}

This section will start with a review of the definitions of cognitive fusion and defusion. Subsequently, we will explore the interrelationship between these processes and the other processes of the inhexaflex and hexaflex. Lastly, we will provide an RFT conceptualization of these processes.

\subsection{Definitions of cognitive fusion and cognitive defusion}


In order to best understand cognitive defusion, it is necessary to explain the associated pathological process cognitive fusion. Table 1 presents definitions of cognitive fusion provided in popular ACT writings.

Table 1. Definitions of cognitive fusion in some ACT books.

\section{Definitions of cognitive fusion}

Hayes and Strosahl (2005): "Human tendency to interact with events on the basis of their verbally ascribed functions rather than their direct functions, while being oblivious to the ongoing relational framing that establishes these functions. The event and ones thinking about it become so fused as to be inseparable and that creates the impression that verbal construal is not present at all" (p. 25). "Speaking technically, fusion is the dominance of particular verbal functions over other directly and indirectly available psychological functions" (p. 39).

Hayes, Strosahl, and Wilson (2012): "In a technical sense, cognitive fusion is a process by which verbal events exert strong stimulus control over responding, to the exclusion of other contextual variables. Phrased differently, fusion is a kind of verbal dominance in behavioral regulation." (p. 69)

Dahl, Stewart, Martell, and Kaplan (2014): "In RFT terms, fusion could be understood to involve a transformation of functions such that people respond in accordance with the literal meaning of their relational framing (i.e., they "buy into" their thoughts)" (p. 80).

Luoma, Hayes, and Walser (2007): "In general terms, cognitive fusion refers to the tendency of human beings to get caught up in the content of what they are thinking so that it dominates over other useful sources of behavioral regulation... The word fuse comes from a word that means "to pour." Metaphorically, it is as if the content of cognition and the world about which we are thinking are poured together until they are one, in much the same way that lemons, water, and sugar can together become lemonade." (p. 13)

Bennett and Oliver (2019): The term fusion is a technical name for the process by which we respond to our thoughts as if they were literal truths. As with any ACT process, it is contextually dependent, which is to say that responding literally is not necessary problematic, but only so when it restricts or prevents actions towards values." (p. 74).

Wilson (2009): "Fusion is the process whereby certain verbal functions of events exert strong stimulus control over responding to the exclusion of other directly and indirectly available psychological functions" (pp. 54-55).
According to the definitions presented previously, cognitive fusion has a metaphoric origin. In these terms, cognitive fusion involves humans' tendency to get caught up in the content of their thinking as if this process and the world are one (e.g., Luoma, Hayes, \& Walser, 2007). As such, individuals may respond to their thoughts as if they were literal truths, which it is also known as "buying into" their thoughts (e.g., Bennett \& Oliver, 2019; Dahl, Stewart, Martell, \& Kaplan, 2014). In more technical terms, cognitive fusion involves the dominance of verbal functions over other direct and indirect psychological functions (Hayes \& Strosahl, 2005; Wilson, 2009). Thus, cognitive fusion refers to behaving under the control of the ongoing transformation of functions without contacting alternative sources of stimulus control.

It is important to remember that cognitive fusion is a midlevel term. As such, the term has proven to have a high clinical utility but also has the common problems that midlevel terms posit. For instance, cognitive fusion is simultaneously used to refer to an outcome, a process, and a general tendency (e.g., McEnteggart, BarnesHolmes, Hussey, \& Barnes-Holmes, 2015). Looking at the definitions presented previously, the general use of the term is as an outcome behavior. In this regard, cognitive fusion could also be called "fused behavior." It is also worth mentioning that it is common to eliminate the term "cognitive" and only using the word "fusion."

Table 2 presents some definitions of cognitive defusion commonly presented in ACT. In summary, "defusion" is an invented word that refers to undoing fusion. Metaphorically, cognitive defusion involves creating a space between the individual and their private events (e.g., Bennett \& Oliver, 2019) or pulling the "person" apart from the "mind" (Hayes et al., 2012). This process allows the individual to contact and consider alternative behaviors, especially those linked to personal values and objectives.

Table 2. Definitions of cognitive defusion in some ACT books.

\section{Definitions of cognitive defusion}


Luoma, Hayes, and Walser (2007): "Defusion is an invented word meaning to undo fusion, or "de-fusion," and refers to the process of creating nonliteral contexts in which language can be seen as an active, ongoing, relational process that is historical in nature and present in the current moment." (p. 18).

Hayes and Strosahl (2005): "Cognitive defusion works by changing the contexts that support detrimental functions that occur through relational learning so that the process of relating dominates over the results of that process... As defusion skills are established, literal language itself is brought under better contextual control. Clinically, we want to teach clients to see thoughts as thoughts, feelings as feelings, memories as memories, and physical sensations as physical sensations. None of these private events are inherently toxic to human welfare when experienced for what they are." (p. 8).

Hayes, Strosahl, and Wilson (2012): "In their more elaborated forms featured in ACT, defusion involves learning to be consciously aware of one's thinking as it occurs" (p. 23). "In order to bring fusion under contextual control, ACT teaches clients how to separate ongoing cognitive process from its cognitive products. Metaphorically, this is tantamount to pulling the "human" (the listener) apart from the "mind" (the speaker)" (p. 24). "Defusion does not eliminate verbal meaning - it just reduces its automatic effect on behavior such that other sources of behavioral regulation can better participate in the moment" (p. 245).

Bennett and Oliver (2019): "When we are able to defuse, thoughts may still be true but they may also not be. We can relate to them less literally. They no longer require immediate attention and are less threatening. As space is created between ourselves and our thinking, there is the opportunity to consider other guides to behavior" (p. 75).

Dahl, Stewart, Martell, and Kaplan (2014): "At its core, this is a process in which people come to experience thoughts as simply thoughts - as fleeting events that they need not directly respond to, challenge, or control." (p. 82).

Wilson (2009): "Defusion means making contact with verbal products as what they are, not as what they say they are" (p. 51).

In more technical terms, cognitive defusion involves being consciously aware of private events as ongoing relational processes to reduce their immediate verbal functions and contact other sources of stimulus control (Hayes et al., 2012; Luoma et al., 2007). Said differently, cognitive defusion refers to seeing thought as thoughts, feelings as feelings, memories as memories, and physical sensations as physical sensations (Hayes \& Strosahl, 2005). When perceiving these private events as they are, their immediate verbal functions are reduced. This process facilitates engaging in verbal activity that allows contacting values and the actions available in this context that advance towards values.

The term cognitive defusion has also demonstrated tremendous clinical utility. However, similar concerns regarding the limitations of midlevel terms apply. In this regard, the term cognitive defusion is simultaneously referred to as a procedure, a process, and an outcome (Assaz, Roche, Kanter, \& Oshiro, 2018). According to the definitions presented previously, it seems that the term cognitive defusion is most frequently used to refer to an outcome: a type of behavior that is not controlled by private events' immediate verbal functions (i.e., defused behavior). As with cognitive fusion, the term "cognitive" is frequently omitted in favor of the word "defusion."

\subsection{Relationships with other ACT midlevel processes}

Cognitive fusion plays a central role in the psychological inflexibility model of psychopathology and behavioral ineffectiveness (Hayes \& Strosahl, 2005). Cognitive fusion is also associated with the other midlevel processes. Briefly, behaving fused hinders present moment awareness and focuses individuals' behavior on unproductive verbalizations about themself. Additionally, fused behavior usually leads to engagement in experiential avoidance strategies when experiencing private events with aversive functions. These detrimental effects of cognitive fusion make it difficult to contact values in the present moment and behave towards valued ends.

Cognitive defusion plays an essential role in the psychological flexibility model of mental health and behavioral effectiveness. Defusing from the immediate functions of private events might allow the individual to accept them, contact with self-as-context and values, and orient behavior towards the committed actions available in the present moment. Thus, developing defusion skills is often a crucial part of ACT. These skills are required to accept aversive private events and make the function of values symbolically present. The work on defusion is especially relevant in ACT when the client frequently experiences aversive private events. Metaphorically, developing defusion skills is a first step 
for the individual to stop acting under the control of aversive verbal functions and behave more wisely.

\subsection{An RFT conceptualization of cognitive (de)fusion}

This section will provide a brief RFT analysis of the phenomena described by the mid-level terms cognitive fusion and cognitive defusion. According to Törneke et al. (2016), the core of psychopathology relies on how individuals respond to the functions of their behavior, which critically includes private events such as thoughts, memories, and emotions. Two types of functions are especially relevant in this context. First, private events have emotional functions that vary in the aversive-appetitive continuum. Second, private events usually have discriminative functions (e.g., approaching vs. avoidance functions). Emotional and discriminative functions are usually originated by derived relations and transformation of functions (see Chapters 4 and 5).

Törneke et al. (2016) suggested that, from a functional point of view, there are two fundamental types of reaction to private events: (a) in coordination with their emotional and discriminative functions, and (b) framing them in hierarchy with the deictic $I$ and responding according to additional relational activity that specifies appetitive augmental functions.

The first type of reaction is more straightforward and will be the dominant one if a fluid and flexible repertoire of framing private events in hierarchy with the deictic $I$ has not been developed. Responding in coordination implies behaving under the control of the immediate functions of private events. Importantly, when the private event has an aversive function, the individual will likely respond according to the discriminative functions of avoidance/escape. The specific form of the avoidance/escaping behavior displayed will depend on multiple factors, such as learning history, the availability of specific responses, and their potential behavioral cost.

Given our extreme fluency in derived relational responding, engaging in further relational responding about the coherence of the private event's content (e.g., worry/rumination) tends to become a predominant experiential avoidance strategy (Ruiz, Luciano, Flórez, Suárez-Falcón, \& Cardona-Betancourt, 2020; Ruiz, Riaño-Hernández, Suárez-Falcón, \& Luciano, 2016). This type of relational responding has especially counterproductive effects when carried out repeatedly. First, it usually generates the paradoxical effect of extending the negative affect because it focuses on aversive emotional content, which usually leads to other avoidance behaviors. Second, it increases the complexity of the relational networks involved in the thinking process and reduces their derivation and flexibility level (Ruiz, Luciano, et al., 2020). These counterproductive effects significantly contribute to the repetition of the avoidance cycle and generate an inflexible behavior pattern that is negatively reinforced and hinders behaving under the control of abstract positive reinforcers.

The second way of reacting to one's behavior is more complex because it consists of framing it in a hierarchy with the deictic $I$. This implies deriving that ongoing private events are momentary experiences that occur in the context of a self that contains them and from where they can be experienced as a product of the learning history. Framing private events in hierarchy leads to a reduction of the discriminative functions and the possibility of engaging in further relational responding that specifies appetitive augmental functions and behavior according to them. This way of responding is more flexible and makes it possible to develop a behavior pattern under the control of abstract positive reinforcers.

The pattern of behavior in which the individual responds in coordination with the discriminative functions of private events resembles the concept of psychological inflexibility in ACT. In contrast, the pattern of behavior consisting of framing private events in hierarchy with the deictic $I$ and responding under the control of appetitive augmentals resembles the concept of psychological flexibility.

This RFT account does not map exactly onto the ACT midlevel processes (Törneke et al., 2016). However, the similarity between cognitive fusion and responding in coordination with private events' discriminative functions is straightforward. Also, there seems to be a high degree of similarity between cognitive defusion and hierarchically framing private events with the deictic $I$. In our view, the advantage of this RFT conceptualization is that it facilitates refining psychological interventions because the basic psychological processes are specified. The section dedicated to reviewing component studies on cognitive 
defusion will mention a series of studies prompted by this RFT conceptualization.

\section{Clinical examples of cognitive defusion and processes of change}

\subsection{Cognitive defusion exercises}

Following Blackledge (2015), defusion exercises can be categorized into five types: (a) language conventions, (b) metaphors, (c) exercises that change language parameters, (d) exercises that promote distancing from private events, and (e) exercises aiming to undermine verbal rules and narratives. Before describing them, it is worth noting that the therapist should establish an adequate context before introducing some defusion exercises because they might seem rather odd to clients and make them feel invalidated (e.g., Blackledge, 2015; Hayes et al., 2012; Wilson \& Luciano, 2002).

Language conventions. Expressions highlighting the nature of private events are usually introduced in ACT. A typical example of these conventions is subtly identifying thoughts as thoughts or as products of the "mind." For instance, when clients make problematic verbalizations (e.g., "The break-up was only my fault."), the ACT therapist often uses expressions like "So, right now you are having the thought that it was your fault" or "Look what your mind is telling you. What a beautiful thought!" Another option to create some distance between the clients and their private events is to talk with them in the third person (e.g., "What did Mark feel when he was at work?"; "It seems family relationships are very important for Beatriz"). The effect of these language conventions might not be very high, but introducing them during the therapy serves to prepare the client for more intensive work in defusion (Blackledge, 2015). Specifically, these language conventions establish frames of distinction and hierarchy between the clients and their private events.

Metaphors. The extensive use of metaphors is a hallmark of ACT. The metaphors can be used to promote defusion by objectifying private events as something different or included in the person (i.e., establishing a hierarchical relation between the client and their private events). A typical example is the "passengers on the bus" metaphor (Hayes et al., 1999). In this metaphor, distressing private events are presented as passengers on a bus the client is driving in a valued direction. Some of the passengers are annoying and verbalize the client's aversive private events. The client has no control over what they say but can choose between driving the bus towards the valued direction or paying attention, fighting, or obeying them. The "passengers on the bus" metaphor has the advantage of targeting virtually all ACT processes at the same time: acceptance (the willingness of the bus driver to stay in contact with the passengers because this serves to advance in the valued direction), defusion (objectifying the challenging private events as the passengers), selfas-context (the bus contains all passengers), present moment awareness (the bus driver's valued action is to focus on driving), values (the bus driver can choose his/her overall direction in life), and committed action (the bus driver can choose their immediate route to advance towards the overall life direction).

Changing language parameters. These exercises manipulate elements of the context that provide psychological functions to thoughts. These exercises aim to highlight the arbitrary nature of thoughts and present them as innocuous experiences (Blackledge, 2007; e.g., a thought can be seen as just a thought: a group of words ordered in a specific way that are pronounced with a specific tone, rate, and manner). Changing the contextual features associated with thoughts' functions can alter their meaning and lead the client to experience them from a different perspective.

The most typical example of this type of exercise is the classic word-repetition exercise (Titchener, 1910). This exercise consists of continuously repeating a word for about half a minute or more. This provokes a profound change in the initial functions of the thought that are substituted by its perceptual, nonarbitrary functions. The exercise procedure usually involves presenting a brief rationale that highlights the arbitrary nature of thoughts. The client is invited to imagine a glass of milk and experience the functions of milk (e.g., it is white, creamy, etc.). Afterward, the client and the therapist quickly repeat the word "milk" until the functions of the word change momentarily. The same procedure is then applied to a distressing thought summarized in one word in order for the clients to realize the arbitrary nature of thoughts and that they can be experienced as transitory experiences in the context of a transcendet self. 
Distancing exercises. These exercises locate private events at a spatial distance from oneself. The clients are then asked just to observe private events without judgment or without reacting to them, with the aim to see thoughts as just thoughts, emotions as just emotions, and so on. A very typical exercise is the "leaves on a stream" exercise. There are different versions of this exercise in ACT texts. We will present a version of the exercise enriched with explicit hierarchical cues and questions to derive appetitive augmentals or regulatory functions (Luciano et al., 2011).

The exercise begins by inviting the clients to discriminate ongoing private events or recall some of the events experienced in difficult situations. They are asked to fully concentrate on one of these events, notice who was having them and imagine them on a leaf in a tree that falls into a river. The clients are asked to notice that their event is now THERE while they are HERE observing it. The therapist asks the clients to suspend judgment (e.g., "Allow yourself not to judge the thought, just contemplate it as like you contemplate a painting or a landscape") and focus on some nonarbitrary characteristics of the event (e.g., "See how many words the thought has and choose a color for the ink"). Subsequently, the therapist asks the clients to discriminate that the event is just a transitory experience they are having, its immediate discriminative functions and that they can choose just to observe this process (e.g., "Who is having this thought? What is it compelling you to do? Note that right now you are choosing just to observe it, that you have the capacity of choosing what to do"). Afterward, the therapist asks questions regarding the available ways of responding to the event (e.g., "What would happen right now if you let the thought to be in charge? What would happen if you let this and other similar thoughts be in charge for another three months? Alternatively, what could you do that imply that you are in charge? What would happen if you do that? What would happen if you respond to this and similar thoughts this way during the next three months?"). Lastly, the therapist invites the client to choose and discriminate that action (e.g., "What do you choose to do here and now? Note that you are the person who is choosing what to do, that you have the capacity to choose wisely the direction you want to take in your life. What would you achieve? How do you feel now, when noticing what you could achieve?).

Undermining verbal rules and narratives. Private events are often considered as causes of subsequent behavior. For instance, clients usually show fusion with reasons for behaving in a particular way without realizing that reasons are not causes; they are only verbalizations that arbitrarily became causes in the person's learning history. A typical defusion exercise used in this regard consists of asking the clients to think about not doing a particular action (e.g., "I will not take the pen on the table") and giving reasons for not doing so (e.g., "It is contaminated," "I will get stained with the ink"), while at the same time asking them to perform it. Then, the clients are asked to think and give reasons for performing the same action (e.g., "I will take the pen on the table," "I need it to write down something important") while also asked not to perform it. The exercise aims to highlight the arbitrary connection between thoughts/reasons and actions. They also highlight that clients can observe thoughts/reasons and choosing to behave according to other sources of stimulus control.

\subsection{Processes involved in cognitive defusion exercises}

Identifying the basic processes underlying the effect of defusion exercises is a complicated task, and research on this topic is still scarce (see section 4.1.2). Blackledge (2007) suggested that defusion exercises seem to work by disrupting the context of literality. This effect is produced when the contextual conditions that provide meaning to thoughts via transformation of functions are displaced. A typical exercise would be the word-repetition exercise that alters the context in which aversive functions occur by focusing the client's attention on the thought's perceptual functions (e.g., the funny sound of the word).

Assaz et al. (2018) suggested that Blackledge's account neglected some learning processes. Central to Assaz et al.'s proposal is the idea that different learning processes can lead to similar outcomes: "Our main argument is that the reduction of transformation of function through verbal relations is an outcome that can be obtained through different basic behavioral processes" (p. 411). The authors provided analysis for different types of defusion exercises. 
Regarding the exercises that focus on changing language parameters, they suggest that these exercises are mainly exposure procedures because the clients repeatedly contact private events without other associated stimulus until its verbally conditioned eliciting functions are reduced. Accordingly, the processes of change in this type of exercise could be the same as those involved in exposure: respondent extinction, counterconditioning, and inhibitory learning.

Defusion exercises that disrupt the link between thoughts and actions (e.g., see the exercise explained in the type "undermining verbal rules and narratives") would work through differential reinforcement. The rationale is that the alternative behaviors to the rigid responses caused by cognitive fusion will be reinforced somehow. This differential reinforcement implies that the thought becomes a discriminative stimulus for other responses.

Assaz et al. (2018) also suggests that some defusion exercises work because they show that thinking is not a coherent narrative depicting reality. Lastly, they suggest that distancing exercises such as the "leaves on a stream" work by locating thoughts at a spatial distance from oneself, which would result in a decrease in their functions.

Despite both proposals' merits, we found at least one relevant omission and two areas where we disagree. The accounts omit that teaching the clients to observe ongoing private events in a way that opens the door to other sources of stimulus control (i.e., framing private events in hierarchy with the deictic $I$; see section 1.3.) is a primary process involved in defusion exercises.

With this omission in mind, the first limitation is that the authors focus their attention on how defusion exercises may disrupt transformation of functions. This seems to be true when practicing some defusion exercises in the therapy room (e.g., word-repetition exercise), but not when behaving outside. In everyday interactions, the extensive learning history in the context of literality will likely prevail over the brief defusion exercises practiced in the therapy room. Thus, "negative" thoughts will more likely elicit aversive functions automatically, and the client will have to respond to these functions in some way. It seems more likely that defusion exercises such as the word-repetition or distancing exercises teach clients to observe thoughts as transitory and arbitrary events. In this way, the thoughts used in the defusion practice (and others symbolically related to them) will probably acquire discriminative functions for framing them in hierarchy with the deictic $I$. This suggestion is in line with the following reference by Hayes et al. (2012): "Defusion does not eliminate verbal meaning - it just reduces its automatic effect on behavior such that other sources of behavioral regulation can better participate in the moment" (p. 245).

Second, we find that both conceptualizations fail to explore the temporal nature of the changes produced by defusion exercises. We will explain this point by commenting on some of Assaz et al.'s suggestions. The authors propose that the exercises that change language parameters (e.g., the word-repetition exercise) are exposure exercises that could work through respondent extinction, counterconditioning, or learning inhibition. Due to the procedure, it seems logical to think this way. However, it seems unlikely that these processes play a significant role in behavior change at the beginning of the therapy. Exposure techniques usually produce changes in behavior after several sessions. Following the idea presented in the previous paragraph, it seems more likely (and also more coherent with our clinical experience) that these exercises provide discriminative functions to frame these thoughts in hierarchy with the deictic $I$. The generation of these discriminative functions seems to be considerably faster than, for example, the respondent extinction that exposure techniques might provoke. Importantly, once the individual begins to frame aversive thoughts in hierarchy with the deictic $I$, instead of responding in coordination with their discriminative avoidance functions, respondent extinction will play a role in decreasing the thoughts' emotional functions. In other words, it seems more likely that respondent extinction occurs after some practice in framing private events in hierarchy with the deictic $I$.

A similar rationale can be applied to the other processes suggested by Assaz et al. (2018). For instance, it is unlikely that defusion exercises will produce sufficient differential reinforcement of alternative responses (DRA) to overcome the clients' previous practice with avoidance responses. It seems more probable that DRA will occur after the client's practice in distancing from the predominant functions of private events. More importantly, when DRA is repeated due to 
framing private events in hierarchy, their predominant discriminative avoidance functions can be changed for other discriminative functions associated with the DRA process.

Our suggestion about the processes involved in defusion exercises highlights the role of hierarchically framing behavior with the deictic $I$. This analysis is derived from the RFT conceptualization presented previously that has produced some empirical analyses that will be presented later (section 4.1.2.). Further experimental analyses are needed to test if framing behavior in hierarchy is the predominant process of change of cognitive defusion exercises.

\section{Measurement of cognitive defusion}

\subsection{Self-report instruments}

Many self-report measures of cognitive defusion have been developed in the last decade. We will focus on those developed following the ACT conceptualization of these processes. Note, however, that other instruments have been developed for the measurement of related constructs such as decentering (Experiences Questionnaire-Decentering Scale - EQ-D; Fresco et al., 2007). Table 3 presents a summary of the cognitive (de)fusion instruments developed to date.

\section{Cognitive Fusion Questionnaire (CFQ;} Gillanders et al., 2014). The CFQ is the most widely used instrument to measure cognitive fusion as a trait and across contexts. It consists of 7 items that are responded to on a 7-point Likert-type scale ( $7=$ always; $1=$ never true), with higher scores indicating a higher degree of cognitive fusion. The original validation study was conducted with a total sample of 1,800 participants (Gillanders et al., 2014). The CFQ demonstrated excellent internal consistency with Cronbach's alpha scores above .88 across samples, good test-retest reliability, a one-factor structure, discriminant validity, construct validity, and sensitivity to treatment effects.

The CFQ has been translated into several languages, including Spanish, French, German, Korean, Catalan, and Italian. These different versions of the CFQ have shown similar psychometric properties to the original (i.e., excellent internal consistency and a onefactor structure) and overall convergent and concurrent validity (China, Hansen, Gillanders, \& Benninghoven, 2018; Dionne et al., 2016; Kim \& Cho, 2015; Oppo et al., 2019; Ruiz, Suárez-Falcón, Riaño-Hernández, \& Gillanders, 2017; Solé et al., 2015).

A state version of the CFQ has also been developed (SCFQ; Bolderston, Gillanders, Turner, Taylor, \& Coleman, 2019). The items of the SCFQ are very similar to the CFQ ones, but they were rewritten to address fusion in the present moment. Additionally, the instructions of the SCFQ ask respondents to indicate how true each statement is for them at this moment. The SCFQ showed excellent internal consistency, a onefactor structure, stability over time, and sensitivity to short-term treatment effects. Accordingly, the SCFQ is especially well-suited to be administered in laboratorybased studies implementing cognitive fusion inductions or analyzing the effect of brief defusion exercises or more general interventions.

The CFQ has also been adapted to specific contexts or disorders, including body image (Cognitive Fusion Questionnaire - Body Image, CFQ-BI; Ferreira, Trindade, Duarte, \& Pinto-Gouveia, 2015), chronic illness (Cognitive Fusion Questionnaire - Chronic Illness, CFQ-CI; Trindade, Barbosa, Ferreira, \& PintoGouveia, 2020; Trindade, Ferreira, \& Pinto-Gouveia, 2018), and food craving (Cognitive Fusion Questionnaire - Food Craving, CFQ-FC; Duarte, PintoGouveia, Ferreira, \& Silva, 2016). The validation studies have found similar psychometric properties to the original $\mathrm{CFQ}$.

Believability of Anxious Feelings and Thoughts Questionnaire (BAFT; Herzberg et al., 2012). The BAFT is a 16-item questionnaire that measures cognitive fusion with anxious thoughts and feelings through a 7-point Likert-type scale $(7=$ completely believable; 1 = not at all believable). The initial validation study was conducted with a total sample of 935 participants, including undergraduates and highly anxious individuals (Herzberg et al., 2012). The BAFT showed excellent internal consistency (Cronbach's alpha of .90 to .91 across samples), a hierarchical factor structure with three lower-order factors and one hierarchical factor, convergent validity, and sensitivity to treatment effects. The BAFT has been translated into Spanish (Ruiz, Odriozola-González, \& Suárez-Falcón, 2014) and Farsi (Mohammadipour \& Ardehaee, 2016), showing similar psychometric properties to the original version. 
Drexel Defusion Scale (DDS; Forman et al., 2012). The DDS is a 10-item self-report measure that evaluates the degree to which an individual defuses from unpleasant internal experiences through a 6-point Likert-type scale $(0=$ not at all; $5=$ very much $)$. The DDS defines defusion in its introduction to facilitate the Table 3. Summary of the self-report instruments designed to measure cognitive (de)fusion.

\begin{tabular}{|c|c|c|c|c|c|c|c|c|c|}
\hline Study & Instrument & $\mathrm{N}$ & $\begin{array}{l}\mathrm{N} . \\
\text { Items }\end{array}$ & Scale & $\alpha$ & $\begin{array}{l}\text { Factor } \\
\text { Structure }\end{array}$ & Population & Items examples & Languages \\
\hline $\begin{array}{l}\text { Gillanders } \\
\text { et al. } \\
(2014)\end{array}$ & $\begin{array}{l}\text { Cognitive } \\
\text { Fusion } \\
\text { Questionnaire } \\
\text { (CFQ) }\end{array}$ & 1800 & 7 & $\begin{array}{l}\text { 7-point } \\
\text { Likert-type } \\
\text { scale }(7= \\
\text { always } ; 1= \\
\text { never true })\end{array}$ & .88 & One-factor & Adults & $\begin{array}{l}\text { "My thoughts } \\
\text { cause me distress } \\
\text { or emotional pain" }\end{array}$ & $\begin{array}{l}\text { English } \\
\text { German } \\
\text { French } \\
\text { Korean } \\
\text { Italian } \\
\text { Spanish }\end{array}$ \\
\hline $\begin{array}{l}\text { Bolderston } \\
\text { et al. } \\
(2019)\end{array}$ & $\begin{array}{l}\text { State version of } \\
\text { the Cognitive } \\
\text { Fusion } \\
\text { Questionnaire } \\
\text { (SCFQ) }\end{array}$ & 379 & 7 & $\begin{array}{l}\text { 7-point } \\
\text { Likert-type } \\
\text { scale }(7= \\
\text { always; } 1= \\
\text { never true })\end{array}$ & .95 & One-factor & Adults & $\begin{array}{l}\text { "I am very } \\
\text { entangled in my } \\
\text { thoughts." }\end{array}$ & English \\
\hline $\begin{array}{l}\text { Ferreira et } \\
\text { al. }(2015)\end{array}$ & $\begin{array}{l}\text { Cognitive } \\
\text { Fusion } \\
\text { Questionnaire - } \\
\text { Body Image } \\
\text { (CFQ-BI) }\end{array}$ & 929 & 10 & $\begin{array}{l}\text { 7-point } \\
\text { Likert-type } \\
\text { scale }(7= \\
\text { always } ; 1= \\
\text { never true })\end{array}$ & .96 & One-factor & Adults & $\begin{array}{l}\text { "I struggle with } \\
\text { my thoughts } \\
\text { related to my body } \\
\text { or physical } \\
\text { appearance" }\end{array}$ & $\begin{array}{l}\text { English } \\
\text { Portuguese }\end{array}$ \\
\hline $\begin{array}{l}\text { Trindade } \\
\text { et al. } \\
(2018)\end{array}$ & $\begin{array}{l}\text { Cognitive } \\
\text { Fusion } \\
\text { Questionnaire- } \\
\text { Chronic Illness } \\
\text { (CFQ) }\end{array}$ & 120 & 7 & $\begin{array}{l}\text { 7-point } \\
\text { Likert-type } \\
\text { scale }(7= \\
\text { always } ; 1= \\
\text { never true })\end{array}$ & .97 & One-factor & Adults & $\begin{array}{l}\text { "I tend to get very } \\
\text { entangled in my } \\
\text { thoughts relating } \\
\text { to my illness } \\
\text { and/or } \\
\text { symptoms." }\end{array}$ & $\begin{array}{l}\text { English } \\
\text { Portuguese }\end{array}$ \\
\hline $\begin{array}{l}\text { Duarte et } \\
\text { al. (2016) }\end{array}$ & $\begin{array}{l}\text { Cognitive } \\
\text { Fusion } \\
\text { Questionnaire- } \\
\text { Food Craving } \\
\text { (CFQ-FC) }\end{array}$ & 872 & 7 & $\begin{array}{l}\text { 7-point } \\
\text { Likert-type } \\
\text { scale }(7= \\
\text { always } ; 1= \\
\text { never true })\end{array}$ & .94 & One-factor & Adults & $\begin{array}{l}\text { "My food-related } \\
\text { thoughts cause me } \\
\text { distress or } \\
\text { emotional pain." }\end{array}$ & $\begin{array}{l}\text { English } \\
\text { Portuguese }\end{array}$ \\
\hline $\begin{array}{l}\text { Herzberg } \\
\text { et al. } \\
(2012)\end{array}$ & $\begin{array}{l}\text { Believability of } \\
\text { Anxious } \\
\text { Feelings and } \\
\text { Thoughts } \\
\text { Questionnaire } \\
\text { (BAFT) }\end{array}$ & 935 & 16 & $\begin{array}{l}\text { 7-point } \\
\text { Likert-type } \\
\text { scale }(7= \\
\text { completely } \\
\text { true } ; 1= \\
\text { completely } \\
\text { untrue })\end{array}$ & .95 & $\begin{array}{l}\text { A hierarchical } \\
\text { factor with } \\
\text { two or three } \\
\text { lower-order } \\
\text { factors }\end{array}$ & Adults & $\begin{array}{l}\text { "I could lose } \\
\text { control of myself } \\
\text { when I feel } \\
\text { anxious or afraid." }\end{array}$ & $\begin{array}{l}\text { English } \\
\text { Farsi } \\
\text { Spanish }\end{array}$ \\
\hline $\begin{array}{l}\text { Forman et } \\
\text { al. }(2012)\end{array}$ & $\begin{array}{l}\text { The Drexel } \\
\text { Defusion Scale } \\
\text { (DDS) }\end{array}$ & 379 & 10 & $\begin{array}{l}\text { 6-point } \\
\text { Liker type } \\
\text { scale }(0= \\
\text { not at all; } 5 \\
=\text { very } \\
\text { much })\end{array}$ & $\begin{array}{l}.83- \\
.80\end{array}$ & One-factor & Adults & $\begin{array}{l}\text { "Anxious } \\
\text { thoughts. Things } \\
\text { have not been } \\
\text { going well at } \\
\text { school or at your } \\
\text { job, and work just } \\
\text { keeps piling up. } \\
\text { To what extent } \\
\text { would you } \\
\text { normally be able } \\
\text { to defuse from } \\
\text { anxious thoughts } \\
\text { like "I'll never get } \\
\text { this done." }\end{array}$ & English \\
\hline
\end{tabular}




\begin{tabular}{|c|c|c|c|c|c|c|c|c|c|}
\hline $\begin{array}{l}\text { Rolffs et } \\
\text { al. (2016) }\end{array}$ & $\begin{array}{l}\text { Multidimension } \\
\text { al Psychological } \\
\text { Flexibility } \\
\text { Inventory } \\
\text { (MPFI) }\end{array}$ & 3040 & 60 & $\begin{array}{l}\text { 6-point } \\
\text { Likert-type } \\
\text { scale }(0= \\
\text { never } ; 5= \\
\text { always })\end{array}$ & $\begin{array}{l}.88 \\
(\mathrm{PF}) \\
.92 \\
(\mathrm{PI})\end{array}$ & $\begin{array}{l}\text { Two higher- } \\
\text { order factors }\end{array}$ & Adults & $\begin{array}{l}\text { "It was very easy } \\
\text { to get trapped into } \\
\text { unwanted } \\
\text { thoughts and } \\
\text { feelings." }\end{array}$ & $\begin{array}{l}\text { English } \\
\text { Mandarin } \\
\text { Japanese }\end{array}$ \\
\hline $\begin{array}{l}\text { Greco et } \\
\text { al. }(2008)\end{array}$ & $\begin{array}{l}\text { Avoidance and } \\
\text { Fusion } \\
\text { Questionnaire } \\
\text { for Youth } \\
\text { (AFQ-Y) }\end{array}$ & 1369 & 17 & $\begin{array}{l}\text { 5-point } \\
\text { Likert-type } \\
\text { scale }(4= \\
\text { very true } ; 0 \\
=\text { not at all } \\
\text { true })\end{array}$ & .83 & $\begin{array}{l}\text { No conclusive } \\
\text { results (one- } \\
\text { factor) }\end{array}$ & $\begin{array}{l}\text { Children } \\
\text { and } \\
\text { Adolescents }\end{array}$ & $\begin{array}{l}\text { "My life won't be } \\
\text { good until I feel } \\
\text { happy," "My } \\
\text { thoughts and } \\
\text { feelings mess up } \\
\text { my life" }\end{array}$ & $\begin{array}{l}\text { English } \\
\text { Persian } \\
\text { Dutch } \\
\text { Spanish } \\
\text { Italian }\end{array}$ \\
\hline
\end{tabular}

participant's understanding of the concept. The initial validation study was conducted with a sample of 379 individuals, including undergraduates and clinical participants. The DDS showed good internal consistency (Cronbach's alpha from .80 to .83), a onefactor structure, and convergent and discriminant validity.

\section{Multidimensional Psychological Flexibility} Inventory (MPFI; Rolffs, Rogge, \& Wilson, 2016). The MPFI is a 60 -item self-report measure that evaluates psychological flexibility and inflexibility through a 6point Likert-type scale ( $5=$ always; $0=$ never $)$. The MPFI was designed to assess the six processes involved in psychological flexibility (i.e., acceptance, contact with the present moment, self as context, cognitive defusion, committed action, and values) and the six processes contained in psychological inflexibility (i.e., experiential avoidance, lack of contact with the present moment, self as content, fusion, inaction, and lack of contact with values). The validation study of the MPFI conducted with a total sample of 3,040 participants showed the expected factor structure with two higherorder factors that contained the six processes of psychological flexibility and inflexibility, respectively (Rolffs et al., 2016; Seidler, Stone, Clark, Koran, \& Drake, 2020). The cognitive fusion and cognitive defusion subscales of the MPFI showed excellent internal consistency and convergent validity. The MPFI has been translated into Mandarin, simplified Mandarin, and Japanese (Lin, Rogge, \& Swanson, 2020).

Avoidance and Fusion Questionnaire - Youth (AFQ-Y; Greco, Lambert, \& Baer, 2008). The AFQ-Y is a self-report measure of psychological inflexibility in children and adolescents. It consists of 17 items that are responded to on a 5-point Likert-type scale ( $4=$ very true; $0=$ not at all true). In the initial validation study, Greco et al. (2008) recruited a total sample of 1,369 children and adolescents. The AFQ-Y showed good internal consistency, a one-factor model, convergent, and construct validity. A short, 8-item version of the AFQ was also created (i.e., AFQ-8). Subsequent studies have found divergences regarding the factor structure of the AFQ, with some studies finding two factors: experiential avoidance and cognitive fusion (Livheim et al., 2016; Renshaw, 2018; Valdivia-Salas, Martín-Albo, Zaldivar, Lombas, \& Jiménez, 2017). However, other studies have found that the one-factor model is adequate (Salazar et al., 2019; Schweiger et al., 2017; Simon \& Verboon, 2016). Conversely, the AFQ-8 has consistently shown to be a unidimensional measure across studies. 
The AFQ-Y has been translated into several languages, including Spanish, Italian, Dutch, and Persian (García-Rubio et al., 2020; Salazar et al., 2019; Schweiger et al., 2017; Simon \& Verboon, 2016; Valdivia-Salas et al., 2017). These adaptations have shown similar psychometric properties to the original version of the AFQ-Y.

\subsection{Behavioral measures}

To our knowledge, no behavioral measures of cognitive (de)fusion have been developed. However, if we conceptualize cognitive fusion as responding in coordination to the transformed or actualized stimulus functions, inhibitory control tests could be seen as cognitive (de)fusion measures. This type of test asks participants to inhibit predominant behaviors and respond under the control of alternative stimulus functions. One of the most widely used inhibitory control tests is the Stroop Color and Word Test (SCWT; Stroop, 1935), in which participants are asked to name the ink color of words disregarding their meaning. For a proficient reader, reading is the predominant behavior response in the presence of words independently to their ink color. To obtain a good performance in the SCWT, the participant has to inhibit the reading and only focus on the ink color's perceptual functions. In the traditional SCWT, the words that generate interference in the participant's performance are color names, which can be considered neutral stimuli. There are, however, a variety of Emotional Stroop Tasks (EST) that include stimuli with relevant functions (Williams, Mathews, \& MacLeod, 1996). These versions of the Stroop Test might be used to measure cognitive fusion with words related to the client's problem (e.g., words related to anxiety, depression, fear, etcetera).

The relationship between inhibitory control and cognitive (de)fusion has only been addressed in a few studies. For instance, Thomas and Bardeen (2020) found that inhibitory control moderated the relationship between cognitive fusion and anxiety (Thomas \& Bardeen, 2020). In another study, Pilecki and McKay (2012) found that participants in the defusion condition reacted slightly faster to the SCWT after being exposed to a negative emotion induction. Further research is needed to explore the suitability of inhibitory control tests as potential behavioral measures of cognitive (de)fusion.

\subsection{Assessing cognitive defusion in the clinical session}

There are no instruments that measure cognitive (de)fusion in clinical sessions to the best of our knowledge. However, some verbal and nonverbal clues could indicate the degree of cognitive fusion that clients experience. For instance, Hayes, Strosahl, and Wilson (2012) suggested that the most common examples are making repetitive statements, frequent comparisons, and constant evaluations that surpass objective descriptions. On some occasions, the client can also seem troubled, confused, or even exhibit signs of having "internal" arguments to decide what to do. The client may also attempt to justify their behavior and motivations. Lastly, cognitive fusion is also exemplified when the client perseveres in their beliefs without considering other perspectives. Blackledge (2015) suggests the following examples as potential cognitive fusion indicators: describing disturbing thoughts as absolute truths without considering other perspectives, an accelerated speech rate, and nonverbal behavior that matches the emotion and intensity of the client. It is also necessary to mention a couple of aspects that should be considered when assessing cognitive fusion in the clinical session. Firstly, cognitive fusion varies among clients, and while a client might recognize some thoughts as just thoughts, they could be entangled with other thoughts. Secondly, cognitive fusion can also occur with positive thoughts, which can be as problematic as fusion with negative ones.

Hayes et al. (2012) mention that signs of progress include: identifying when the thought process starts, categorizing thoughts as thoughts, and using a more descriptive discourse with fewer evaluations and comparisons. Blackledge (2015) mentioned additional examples, such as a relatively slower speech rate, using metaphors to describe internal experiences, less negative or positive emotional content in speech, separating oneself from one's thoughts, and acknowledging that thoughts are not equal to absolute truths.

\section{Research on cognitive defusion}

\subsection{Component and laboratory research}

We have identified approximately 40 experimental studies analyzing a wide array of cognitive defusion exercises. Because in some cases it is not easy to differentiate defusion from self-as-context exercises, we 
have judiciously included studies in this section. The dependent variables used across studies can be categorized in believability and emotional distress of private events and behavioral measures reflecting psychological flexibility. This section will differentiate studies that compared the relative efficacy of cognitive defusion interventions versus other strategies and studies that analyzed the variables involved in the effect of defusion exercises.

\subsubsection{Laboratory research comparing cognitive defusion versus other strategies}

Cognitive defusion has shown to be more effective than inactive control and placebo conditions in increasing pain tolerance (Carrasquillo, Nakisha, \& Zettle, 2014), distress (Hinton \& Gaynor, 2010), and decreasing thought believability (Prudenzi et al., 2019). Cognitive defusion conditions are also considered more efficacious than experiential avoidance (Hooper, Dack, Karekla, Niyazi, \& McHugh, 2018), thought control (Gutiérrez, Luciano, Rodríguez, \& Fink, 2004; Masuda, Hayes, Sackett, \& Twohig, 2004; McMullen et al., 2008), thought suppression (Hooper, Sandoz, Ashton, Clarke, \& McHugh, 2012), distraction (Hooper \& McHugh, 2013; Mandavia et al., 2015; Masuda, Hayes, Sackett, \& Twohig, 2004; Masuda, Feinstein, Wendell, \& Sheehan, 2010; Masuda, Twohig, et al., 2010; Ritzert, Forsyth, Berghoff, Barnes-Holmes, \& Nicholson, 2015), self-affirmations (Brandrick, Hooper, Roche, Kanter, \& Tyndall, 2020), and general motivational protocols (Luciano et al., 2014). Schumacher, Kemps, and Tiggemann $(2017,2018)$ found that cognitive defusion was more efficacious than guided imagery in resisting food cravings in a general sample of women, but equivalent in clinical samples of food cravers.

We have identified eight studies that compared the efficacy of cognitive defusion versus cognitive restructuring. The results showed equivalent efficacy in five of these studies (Barrera, Szafranski, Ratcliff, Garnaat, \& Norton 2016; Beadman et al., 2015; Deacon, Fawzy, Lickel, \& Wolitzky-Taylor, 2011; Donati et al., 2019; Yovel, Mor, \& Shakarov, 2014). However, three studies showed that cognitive defusion was more efficacious than cognitive restructuring (Karekla et al., 2020; Larsson, Hooper, Osborne, Bennett, \& McHugh, 2016; Moffitt, Brinkworth, Noakes, \& Mohr, 2012). Two of these three studies tested the efficacy of the interventions in food cravings (Karekla et al., 2020;
Moffitt et al., 2012). In conclusion, cognitive defusion interventions seem at least as efficacious as cognitive restructuring, with some evidence that they might be more effective in some contexts, such as resisting food cravings.

\subsubsection{Variables involved in the effect of defusion exercises}

Component studies have been conducted with two types of cognitive defusion exercises: deliteralization and distancing. The studies analyzing deliteralization exercises have used the classic word repetition technique (WRT; Titchener, 1910). Masuda et al. (2009) found that the reduction of emotional discomfort and thought believability was higher when a self-relevant negative thought was rapidly repeated during 20-30 seconds compared to smaller periods. Tyndall, Papworth, Roche, and Bennett (2017) compared three rates of the repetition of a negative thought: $0.5,1$, and 2 seconds. The rates of 0.5 and 1 seconds were more effective than the 2-second rate in reducing thought believability and emotional discomfort.

Following the RFT conceptualization presented before, Luciano et al. (2011) differentiated the type of relational framings involved in distancing exercises for the first time. In a preliminary study with at-risk adolescents, the authors analyzed the differential effect of two defusion protocols: Defusion I and Defusion II. Defusion I involved framing ongoing behavior only through deictic framings (I-Here, Behavior-There). This perspective allows observing the ongoing private events with distance and without judging them. Defusion II added hierarchical framings and questions to promote regulatory functions to the verbal discrimination of private events. Hierarchical framings were added with the aim to derive an explicit relation of inclusion between the individual and their private events. These interactions promoted the experience of the self as a consistent locus for all private events (e.g., "I am more than all my thoughts," "This thought is only a transitory experience I am having," etc.). The promotion of regulatory functions involved questions to explicitly derive appetitive augmentals that allow contacting with values and the actions in coordination with them at that moment. In other words, these interactions were directed to facilitate making a choice according to the individual's values. The results showed that Defusion II had a greater effect on reducing the frequency of 
problematic behaviors and psychological inflexibility at the 4-month follow-up.

The results of the previous study have been replicated in four experimental analogs. Foody, BarnesHolmes, Barnes-Holmes, and Luciano (2013) found that Defusion II (called "hierarchical self as context") was more efficacious in reducing experimentally induced emotional distress than Defusion I. Similarly, Foody, Barnes-Holmes, Barnes-Holmes, Rai, and Luciano (2015) found that protocols that included framing ongoing private events through hierarchical relations were more efficacious than those that only introduced deictic relations. Gil-Luciano, Ruiz, Valdivia-Salas, and Suárez-Falcón (2017) showed that the Defusion II protocol was more effective in promoting tolerance of discomfort induced by the cold-pressor task and aversive films than the Defusion I protocol and a control condition. These changes were produced in the absence of reductions in the discomfort experienced by the participants. Lastly, López-López and Luciano (2017) replicated the previous findings in a cognitive demanding task that provoked discomfort - the Paced Auditory Serial Addition Task-Computerized (PASATC; Lejuez, Kahler, \& Brown, 2003). Participants in the Defusion II protocol showed greater performance improvements than participants in Defusion I and the control condition. There was no difference between participants in Defusion I and the control condition. As in the previous study, the advantage of Defusion II was produced in the absence of significant reductions in discomfort compared to the other experimental conditions. These findings mean that Defusion II protocols affected behavioral tasks' performance by modifying the discriminative functions of aversive private events, but not the emotional functions.

In conclusion, research is advancing in identifying some of the components of cognitive defusion exercises that maximize their effect. In the WRT, the empirical evidence indicates that it is important to repeat the negative thought for at least 20-30 seconds and a repetition rate of 0.5 to 1 seconds. The empirical evidence also shows that including explicit hierarchical framings between the individual and their private events, and providing regulatory functions to this discrimination, enhances the efficacy of typical distancing exercises, such as the "leaves on the stream" (Hayes et al., 1999). Although further research is needed to identify the relational processes involved in the efficacy of defusion exercises, the existing empirical evidence has the potential to improve the efficacy of these exercises and, consequently, ACT interventions.

\subsection{Survey research}

Multiple studies have been conducted during the last decade showing the pernicious role of cognitive fusion. For instance, cognitive fusion has shown strong positive associations with depression and anxiety (Bardeen \& Fergus, 2016; O'Loughlin, Bennett, \& O'Hayer, 2020; Pinto-Gouveia, Dinis, Gregório, \& Pinto, 2020; Sood \& Newman-Taylor, 2020), posttraumatic stress disorder (Bardeen \& Fergus, 2016; Basharpoor, Mowlaie, \& Sarafrazi, 2020; Cox, Motl, Bakker, \& Lunt, 2018; Russell, Bardeen, Clayson, Dolan, \& Fergus, 2020), pain (Angarita-Osorio et al., 2020; Carvalho, Trindade, Gillanders, Pinto-Gouveia, \& Castilho, 2019; Özkan, Zale, Ring, \& Vranceanu, 2017), harmful body image beliefs (Melo, Oliveira, \& Ferreira, 2019; Trindade \& Ferreira, 2015; Trindade, Ferreira, \& Pinto-Gouveia, 2018; Zucchelli, White, \& Williamson, 2020), and eating disorders (Duarte \& Pinto-Gouveia, 2017; Scardera, Sacco, Di Sante, \& Booij, 2020).

Cognitive fusion has also been negatively correlated with values (Berghoff, Ritzert, \& Forsyth, 2018) and life satisfaction (Flynn, Hernandez, Hebert, James, \& Kusick, 2018; Ruiz et al., 2019). Fewer studies have been conducted analyzing the associations of cognitive defusion with mental health and quality of life. However, as expected, cognitive defusion has shown negative correlations with emotional symptoms and positive correlations with values and quality of life (Forman et al., 2012; Rolffs et al., 2016).

Some longitudinal studies have been conducted analyzing cognitive fusion's role in exacerbating psychological and health symptoms. For instance, Carvalho et al. (2019) conducted a study with 86 women experiencing chronic pain to analyze if cognitive fusion predicted depressive symptomatology over 12 months. The results showed that cognitive fusion predicted depressive symptomatology at baseline and its changes during the 12 months of study. Cookson, Luzon, Newland, and Kingston (2020) conducted a longitudinal study over six weeks with a sample of 97 nonclinical participants to analyze whether experiential avoidance and cognitive fusion mediated the effect of worry, rumination, and stressful life-events on emotional 
symptoms. The results showed that cognitive fusion independently mediated the association between the predictors and outcomes.

Ruiz and Odriozola-González (2017) found that cognitive fusion longitudinally mediated the relationship between negative metacognitive beliefs and anxiety and stress symptoms in a nonclinical sample of 106 participants over a lapse of 9 months. Lastly, Trindade et al. (2018) conducted a study with 116 patients with inflammatory bowel disease over 18 months. Cognitive fusion presented a negative correlation with psychological and physical health symptoms and influenced changes in these symptoms during the course of the study.

\subsection{Process of change in clinical interventions}

Parallel to the development of cognitive (de)fusion measures, an increasing number of clinical trials have analyzed whether cognitive defusion worked as a process of change in ACT interventions; preliminary responses to this question support the role of cognitive defusion as an important process of change in ACT. For instance, cognitive defusion has acted as a mediator in participants with anxiety disorders (Arch, WolitzkyTaylor, Eifert, \& Craske, 2012), social anxiety (Krafft, Twohig, \& Levin, 2020), residual depression symptoms (Østergaard, Lundgren, Zettle, Landrø, \& Haaland, 2020), undergraduates with anxiety and depression (Forman et al., 2012), distressed and non-distressed college students (Levin, Krafft, \& Twohig, 2020; Morin, Grégoire, \& Lachance, 2020), stressed parents of children with autism (Blackledge \& Hayes, 2006; Fung, Lake, Steel, Bryce, \& Lunsky, 2018), tinnitus-related stress (Hesser, Westin, Hayes, \& Andersson, 2009), and in promoting mental health in undergraduate students (Viskovich \& Pakenham, 2020). Interestingly, there is also some evidence supporting the role of cognitive defusion as a process of change in other therapies, including cognitive-behavioral therapy (Arch et al., 2012).

\section{Challenges and future research directions}

Although the advance of cognitive defusion research is undeniable, there are still significant challenges and areas in which further work is needed. We will highlight some of them in the following paragraphs.

\subsection{Challenges and future directions for research}

We are going to identify five main limitations in the current research on cognitive defusion. First, behavioral measures of cognitive (de)fusion have not been developed. Developing this type of measure seems important to complement self-report measures and establish bridges with other literature (e.g., executive functioning). In this sense, we have suggested that inhibitory control tests such as the classical Stroop test and some of its variations might be analyzed as potential cognitive fusion measures. Second, although the advance in the measurement of cognitive (de)fusion through self-report is relevant, few attempts to develop measures appropriate for ecological momentary assessment (EMA) studies have been conducted. The popularity of EMA studies is increasing, notably in the last years. They seem to be a promising tool to analyze the efficacy and processes of change of psychological interventions at the individual level due to the intensive measurement they involve.

Third, more component studies of the verbal processes involved in defusion exercises are needed. These studies are advancing in the identification of some of these processes, but further refinements are needed. For instance, the studies analyzing distancing exercises have compared the effect of deictic framing (called Defusion I) versus deictic framing + hierarchical framing + cues to provide regulatory functions (called Defusion II). However, no published studies have analyzed, for example, the effect of separating hierarchical framing interactions from cues to provide regulatory functions (but see the unpublished doctoral thesis by López, 2016). Other combinations of these three components also deserve to be investigated, and additional components can be identified (e.g., hierarchically framing the displayed valued behavior after defusing from aversive private events, see López, 2016). Lastly, we recommend analyzing the effect of the verbal processes involved in defusion in behavioral measures resembling psychological flexibility because they are more similar to the aim of the defusion exercises in clinical interventions than measures of distress or believability.

Fourth, defusion exercises can be applied to all types of private events, such as thoughts, emotions, and memories. However, to our best knowledge, there is no 
published empirical evidence regarding the potential differential effect of directing defusion exercises to different types of private events. Is it more efficacious to use defusion with aversive and personally-relevant private events than neutral private events? The most related research in this regard is the study conducted by Gil-Luciano, Tovar, Calderón-Hurtado, Sebastián, and Ruiz (submitted) with triggers for repetitive negative thinking (RNT). Gil-Luciano, Calderón-Hurtado, Tovar, Sebastián, and Ruiz (2019) found that triggers for RNT (i.e., worry, rumination) are usually organized in hierarchical networks, with a hierarchical trigger symbolically containing other more concrete triggers. Gil-Luciano et al. (submitted) tested the differential effect of Defusion I and Defusion II interventions either directed to the hierarchical trigger or a trigger in a lowerlevel of the hierarchy. The results showed that the Defusion II protocol directed to the hierarchical trigger was more effective than the remaining combinations and a control condition in reducing the detrimental effects of a rumination-induction procedure. These results are consistent with the proposal made in RNT-focused ACT protocols for identifying the hierarchy of triggers for RNT and directing the clinical intervention to the hierarchical trigger (e.g., Ruiz, Luciano, et al., 2020; Ruiz et al., 2016; Ruiz, Peña-Vargas et al., 2020). The study by Gil-Luciano et al. (submitted) opens an interesting research line that deserves further empirical analyses.

Lastly, more studies analyzing the role of cognitive defusion as a process of change in ACT and other psychological therapies are needed. The empirical evidence to date supports the mediator role of cognitive defusion in the treatment effect of ACT. However, the number of studies is still small, and the mediation analyses have been conducted at a nomothetic level. Further studies might use EMA methodology to analyze the mediator role of cognitive defusion at the individual level.

\subsection{Challenges and future directions for clinical work}

There are also some relevant challenges for the clinical work in cognitive defusion that deserve attention. We are going to highlight three of them. First, there is a wide range of tools to promote cognitive defusion. However, it has not been established what type of exercises might be more effective or in which order to introduce them. Are distancing exercises more effective than metaphors or deliteralization exercises? Is it better to begin the intervention in cognitive defusion with experiential exercises than with metaphors to avoid intellectualizing this process?

Second, some cognitive defusion exercises might be too abstract to use them with younger clients. Few studies have specified the appropriate exercises for different developmental levels. In this sense, the RFT conceptualization of psychological flexibility might help to specify the minimum verbal repertoire needed to use cognitive defusion exercises (e.g., Luciano, Valdivia-Salas, Cabello, \& Hernández, 2009; Ruiz \& Perete, 2015). In case the child or adolescent does not have this minimum verbal repertoire, the relational framings involved might be first trained (Fryling, Rehfeldt, Tarbox, \& Hayes, 2020).

Lastly, the research found in component studies of cognitive defusion should be transferred to the practitioner's work in order to improve the efficacy of ACT. Accordingly, ACT manuals and protocols should introduce these findings to enhance the connection between basic and applied research.

\section{Conclusions}

Cognitive defusion is one of the most studied ACT midlevel processes. The review conducted in this chapter indicates that (a) there is a growing number of self-report measures of cognitive (de)fusion with the CFQ being the most analyzed, (b) cognitive defusion protocols have shown to be more effective than most of the strategies with which they have been compared, (c) component studies have advanced in identifying some of the variables involved in the efficacy of deliteralization and distancing exercises, (d) multiple cross-sectional and longitudinal studies have shown the pernicious role of cognitive fusion, and the adaptive role of cognitive defusion, and (e) reductions of cognitive fusion have shown to mediate the effect of ACT and other forms of psychological interventions in clinical trials. Additional research is needed in areas such as measurement, component studies, mediation analyses, and how practitioners could adopt the findings from experimental evidence that might foster the effect of ACT. 


\section{References}

Angarita-Osorio, N., Pérez-Aranda, A., FeliuSoler, A., Andrés-Rodríguez, L., Borràs, X., Suso-Ribera, C., ... \& Luciano, J. V. (2020). Patients with fibromyalgia reporting severe pain but low impact of the syndrome: Clinical and pain-related cognitive features. Pain Practice: The Official Journal of World Institute of Pain, 20 , 255-261 https://doi.org/10.1111/papr.12847

Arch, J. J., Wolitzky-Taylor, K. B., Eifert, G. H., \& Craske, M. G. (2012). Longitudinal treatment mediation of traditional cognitive behavioral therapy and acceptance and commitment therapy for anxiety disorders. Behaviour Research and Therapy, 50, 469-478.

Assaz, D. A., Roche, B., Kanter, J. W., \& Oshiro, C. K. (2018). Cognitive defusion in acceptance and commitment therapy: What are the basic processes of change? The Psychological Record, 68, 405-418.

Bardeen, J. R., \& Fergus, T. A. (2016). The interactive effect of cognitive fusion and experiential avoidance on anxiety, depression, stress and posttraumatic stress symptoms. Journal of Contextual Behavioral Science, 5, 1-6. https://doi.org/10.1016/j.jcbs.2016.02.002

Barrera, T. L., Szafranski, D. D., Ratcliff, C. G., Garnaat, S. L., \& Norton, P. J. (2016). An experimental comparison of techniques: Cognitive defusion, cognitive restructuring, and in-vivo exposure for social anxiety. Behavioural and Cognitive Psychotherapy, 44, 249-254. https://doi.org/10.1017/S13524658140006 30

Basharpoor, S., Mowlaie, M., \& Sarafrazi, L. (2020). The Relationships of Distress Tolerance, Self-compassion to Posttraumatic Growth, the Mediating Role of Cognitive Fusion. Journal of Aggression, Maltreatment \& Trauma, 112.

https://doi.org/10.1080/10926771.2019.17 11279

Beadman, M., Das, R. K., Freeman, T. P., Scragg, P., West, R., \& Kamboj, S. K. (2015). A comparison of emotion regulation strategies in response to craving cognitions: Effects on smoking behaviour, craving and affect in dependent smokers. Behaviour Research and Therapy, 69, 2939.

https://doi.org/10.1016/j.brat.2015.03.013

Bennett, R., \& Oliver, J. E. (2019). Acceptance and commitment therapy: 100 key points and techniques. London: Routledge.

Berghoff, C. R., Ritzert, T. R., \& Forsyth, J. P. (2018). Value-guided action: Within-day and lagged relations of experiential avoidance, mindful awareness, and cognitive fusion in a nonclinical sample. Journal of Contextual Behavioral Science, 10 ,

$19-23$. https://doi.org/10.1016/j.jcbs.2018.07.005

Blackledge, J. T. (2007). Disrupting verbal processes: Cognitive defusion in acceptance and commitment therapy and other mindfulness-based psychotherapies. The Psychological Record, 57, 555-576.

Blackledge, J. T. (2015). Cognitive defusion in practice: A clinician's guide to assessing, observing, and supporting change in your client. New Harbinger Publications.

Blackledge, J. T., \& Hayes, S. C. (2006). Using acceptance and commitment training in the support of parents of children diagnosed with autism. Child \& Family Behavior Therapy, 28, 1-18. https://doi.org/10.1300/J019v28n01_01

Bolderston, H., Gillanders, D. T., Turner, G., Taylor, H. C., \& Coleman, A. (2019). The 
initial validation of a state version of the Cognitive Fusion Questionnaire. Journal of Contextual Behavioral Science, 12, 207-215.

https://doi.org/10.1016/j.jcbs.2018.04.002

Brandrick, C., Hooper, N., Roche, B., Kanter, J., \& Tyndall, I. (2020). A comparison of ultra-brief cognitive defusion and positive affirmation interventions on the reduction of public speaking anxiety. The Psychological Record, 1-9. https://doi.org/10.1007/s40732-02000432-z

Carvalho, S. A., Trindade, I. A., Gillanders, D., Pinto-Gouveia, J., \& Castilho, P. (2019). Cognitive fusion and depressive symptoms in women with chronic pain: A longitudinal growth curve modelling study over 12 months. Clinical Psychology \& Psychotherapy, 26, 616-625. https://doi.org/10.1002/cpp.2386

Carrasquillo, N., \& Zettle, R. D. (2014). Comparing a brief self-as-context exercise to control-based and attention placebo protocols for coping with induced pain. The Psychological Record, 64, 659-669. https://doi.org/10.1007/s40732-014-00743

Cederberg, J. T., Weineland, S., Dahl, J., \& Ljungman, G. (2018). A preliminary validation of the Swedish short version of the avoidance and fusion questionnaire for youth (AFQ-Y8) for children and adolescents with cancer. Journal of Contextual Behavioral Science, 10, 103107.

https://doi.org/10.1016/j.jcbs.2018.09.004

China, C., Hansen, L. B., Gillanders, D. T., \& Benninghoven, D. (2018). Concept and validation of the German version of the Cognitive Fusion Questionnaire (CFQ-D). Journal of Contextual Behavioral Science, 9, 30-35. https://doi.org/10.1016/j.jcbs.2018.06.003
Christodoulou, A., Michaelides, M. P., \& Karekla, M. (2018). Greek version of the Avoidance and Fusion Questionnaire for Youth: Psychometric evaluation and gender multigroup invariance in adolescents. Journal of Psychoeducational Assessment, $\quad 36$, 844-849. https://doi.org/10.1177/073428291771350 0

Cookson, C., Luzon, O., Newland, J., \& Kingston, J. (2020). Examining the role of cognitive fusion and experiential avoidance in predicting anxiety and depression. Psychology and Psychotherapy: Theory, Research and Practice, 93, 456-473. https://doi.org/10.1111/papt.12233

Cox, D. W., Motl, T. C., Bakker, A. M., \& Lunt, R. A. (2018). Cognitive fusion and posttrauma functioning in veterans: Examining the mediating roles of emotion dysregulation. Journal of Contextual Behavioral Science, 8, 1-7. https://doi.org/10.1016/j.jcbs.2018.02.002

Dahl, J., Stewart, I., Martell, C. R., \& Kaplan, J. S. (2014). ACT and RFT in relationships: Helping clients deepen intimacy and maintain healthy commitments using acceptance and commitment therapy and relational frame theory. Oakland, CA: New Harbinger.

Deacon, B. J., Fawzy, T. I., Lickel, J. J., \& Wolitzky-Taylor, K. B. (2011). Cognitive defusion versus cognitive restructuring in the treatment of negative self-referential thoughts: An investigation of process and outcome. Journal of Cognitive Psychotherapy, 25, 218-232. https://doi.org/10.1891/08898391.25.3.218

Dionne, F., Gagnon, J., Balbinotti, M., Peixoto, E., Martel, M. E., Gillanders, D., \& Monestès, J. L. (2016). "Buying Into Thoughts": Validation of a French 
Translation of the Cognitive Fusion Questionnaire. Canadian Journal of Behavioural Science/Revue canadienne des sciences du comportement, 48(4), 278285. https://doi.org/10.1037/cbs0000053

Donati, M. R., Masuda, A., Schaefer, L. W., Cohen, L. L., Tone, E. B., \& Parrott, D. J. (2019). Laboratory analogue investigation of defusion and reappraisal strategies in the context of symbolically generalized avoidance. Journal of the Experimental Analysis of Behavior, 112, 225-241. https://doi.org/10.1002/jeab.550

Duarte, C., \& Pinto-Gouveia, J. (2017). The impact of early shame memories in Binge Eating Disorder: The mediator effect of current body image shame and cognitive fusion. Psychiatry Research, 258, 511517.

https://doi.org/10.1016/j.psychres.2017.08 .086

Duarte, C., Pinto-Gouveia, J., Ferreira, C., \& Silva, B. (2016). Caught in the struggle with food craving: Development and validation of a new cognitive fusion measure. Appetite, 101, 146-155. https://doi.org/10.1016/j.appet.2016.03.00 4

Gil-Luciano, B., Ruiz, F. J., Valdivia-Salas, S., \& Suárez-Falcon, J. C. (2017). Promoting psychological flexibility on tolerance tasks: framing behavior through deictic/hierarchical relations and specifying augmental functions. The Psychological Record, 67, 1-10. https://doi.org/10.1007/s40732-016-02005

Ferreira, C., Trindade, I. A., Duarte, C., \& PintoGouveia, J. (2015). Getting entangled with body image: Development and validation of a new measure. Psychology and Psychotherapy: Theory, Research and Practice, 88, 304-316. https://doi.org/10.1111/papt.12047
Flynn, M. K., Hernandez, J. O., Hebert, E. R., James, K. K., \& Kusick, M. K. (2018). Cognitive fusion among hispanic college students: Further validation of the Cognitive Fusion Questionnaire. Journal of Contextual Behavioral Science, 7, 2934.

https://doi.org/10.1016/j.jcbs.2017.11.003

Foody, M., Barnes-Holmes, Y., Barnes-Holmes, D., \& Luciano, C. (2013). An empirical investigation of hierarchical versus distinction relations in a self-based ACT exercise. International Journal of Psychology and Psychological Therapy, 13, 373-388.

Foody, M., Barnes-Holmes, Y., Barnes-Holmes, D., Rai, L., \& Luciano, C. (2015). An empirical investigation of the role of self, hierarchy, and distinction in a common ACT exercise. The Psychological Record, 65 , 231-243. https://doi.org/10.1007/s40732-014-01032

Forman, E. M., Chapman, J. E., Herbert, J. D., Goetter, E. M., Yuen, E. K., \& Moitra, E. (2012). Using session-by-session measurement to compare mechanisms of action for acceptance and commitment therapy and cognitive therapy. Behavior Therapy, 43, 341-354. https://doi.org/10.1016/j.beth.2011.07.004

Forman, E. M., Herbert, J. D., Juarascio, A. S., Yeomans, P. D., Zebell, J. A., Goetter, E. M., \& Moitra, E. (2012). The Drexel Defusion Scale: A new measure of experiential distancing. Journal of Contextual Behavioral Science, 1, 55-65. https://doi.org/10.1016/j.jcbs.2012.09.001

Fresco, D. M., Moore, M. T., van Dulmen, M. H., Segal, Z. V., Ma, S. H., Teasdale, J. D., \& Williams, J. M. G. (2007). Initial psychometric properties of the experiences questionnaire: validation of a self-report measure of decentering. Behavior 
Therapy, 38, 234-246. https://doi.org/10.1016/j.beth.2006.08.003 Fryling, M., Rehfeldt, R. A., Tarbox, J., \& Hayes, L. J. (Eds.). (2020). Applied behavior analysis of language and cognition: Core concepts and principles for practitioners. Oakland, CA: New Harbinger.

Fung, K., Lake, J., Steel, L., Bryce, K., \& Lunsky, Y. (2018). ACT processes in group intervention for mothers of children with autism spectrum disorder. Journal of Autism and Developmental Disorders, 48(8), 2740-2747. https://doi.org/10.1007/s10803-018-3525$\mathrm{x}$

García-Rubio, C., Lecuona, O., Blanco Donoso, L. M., Cantero-García, M., Paniagua, D., \& Rodríguez-Carvajal, R. (2020). Spanish validation of the short-form of the Avoidance and Fusion Questionnaire (AFQ-Y8) with children and adolescents. Psychological Assessment, 32, e15-e27. https://doi.org/10.1037/pas0000801

Gecht, J., Kessel, R., Mainz, V., Gauggel, S., Drueke, B., Scherer, A., \& Forkmann, T. (2014). Measuring decentering in selfreports: psychometric properties of the Experiences Questionnaire in a German sample. Psychotherapy Research, 24, 6779.

https://doi.org/10.1080/10503307.2013.82 1635

Gil-Luciano, B., Calderón-Hurtado, T., Tovar, D., Sebastián, B., \& Ruiz, F. J. (2019). How are triggers for repetitive negative thinking organized? A relational frame analysis. Psicothema, 31, 53-59.

Gillanders, D. T., Bolderston, H., Bond, F. W., Dempster, M., Flaxman, P. E., Campbell, L., Kerr, S., Tansey, L., Noel, P., Ferenbach, C., Masley, S., Roach, L., Lloyd, J., May, L., Clarke, S., \& Remington, B. (2014). The development and initial validation of the cognitive fusion questionnaire. Behavior Therapy, 45 , 83-101. https://doi.org/10.1016/j.beth.2013.09.001

Greco, L. A., Lambert, W., \& Baer, R. A. (2008). Psychological inflexibility in childhood and adolescence: Development and evaluation of the Avoidance and Fusion Questionnaire for Youth. Psychological Assessment, 20, 93-102. https://doi.org/10.1037/1040-3590.20.2.93

Gregório, S., Pinto-Gouveia, J., Duarte, C., \& Simões, L. (2015). Expanding research on decentering as measured by the Portuguese version of the Experiences Questionnaire. The Spanish Journal of Psychology, 18, E23. https://doi.org/10.1017/sjp.2015.18

Gutiérrez, O., Luciano, C., Rodríguez, M., \& Fink, B. C. (2004). Comparison between an acceptance-based and a cognitivecontrol-based protocol for coping with pain. Behavior Therapy, 35, 767-783.

Hanley, A. W., Bernstein, A., Nakamura, Y., Hadash, Y., Rojas, J., Tennant, K. E., Jensen, R. L., \& Garland, E. L. (2020). The Metacognitive Processes of Decentering Scale: Development and initial validation of trait and state versions. Psychological Assessment, $\quad 32, \quad 956-971$. https://doi.org/10.1037/pas0000931

Hayes, S. C., \& Strosahl, K. D. (2005). A practical guide to acceptance and commitment therapy. NY: Springer.

Hayes, S. C., Strosahl, K. D., \& Wilson, K. G. (1999). Acceptance and commitment therapy. An experiential approach to behavior change. New York: Guilford Press.

Hayes, S. C., Strosahl, K. D., \& Wilson, K. G. (2012). Acceptance and commitment therapy: The process and practice of mindful change. New York, NY: Guilford Press

Hekmati, I., Ranjbar, H. A., \& HajiSaghati, R. (2020). Persian adaptation of avoidance 
and fusion questionnaire for youth (AFQY): A preliminary examination of its psychometric properties. Journal of Contextual Behavioral Science, 17, 46-54. https://doi.org/10.1016/j.jcbs.2020.05.004

Herzberg, K. N., Sheppard, S. C., Forsyth, J. P., Credé, M., Earleywine, M., \& Eifert, G. H. (2012). The Believability of Anxious Feelings and Thoughts Questionnaire (BAFT): a psychometric evaluation of cognitive fusion in a nonclinical and highly anxious community sample. Psychological Assessment, $\quad 24, \quad 877-891$. https://doi.org/10.1037/a0027782

Hesser, H., Westin, V., Hayes, S. C., \& Andersson, G. (2009). Clients' in-session acceptance and cognitive defusion behaviors in acceptance-based treatment of tinnitus distress. Behaviour Research and Therapy, 47, 523-528. https://doi.org/10.1016/j.brat.2009.02.002

Hinton, M., \& Gaynor, S. (2010). Cognitive Defusion for Psychological Distress, Dysphoria, and Low Self-Esteem: A Randomized Technique Evaluation Trial of Vocalizing Strategies. International Journal of Behavioral \& Consultation Therapy, 6, 164-185. http://dx.doi.org/10.1037/h0100906

Hollon, S. D., \& Kendall, P. C. (1980). Cognitive self-statements in depression: development of an automatic thoughts questionnaire. Cognitive Therapy and Research, 4, 383395. https://doi.org/10.1007/BF01178214.

Hooper, N., Dack, C., Karekla, M., Niyazi, A., \& McHugh, L. (2018). Cognitive defusion versus experiential avoidance in the reduction of smoking behaviour: an experimental and preliminary investigation. Addiction Research \& Theory, 26, 414-420. https://doi.org/10.1080/16066359.2018.14 34156
Hooper, N., \& McHugh, L. (2013). Cognitive defusion versus thought distraction in the mitigation of learned helplessness. The Psychological Record, 63, 209-218. https://doi.org/10.11133/j.tpr.2013.63.1.0 16

Hooper, N., Sandoz, E. K., Ashton, J., Clarke, A., $\&$ McHugh, L. (2012). Comparing thought suppression and acceptance as coping techniques for food cravings. Eating Behaviors, $\quad 1, \quad 62-64$. https://doi.org/10.1016/j.eatbeh.2011.10.0 02

Karekla, M., Georgiou, N., Panayiotou, G., Sandoz, E. K., Kurz, A. S., \& Constantinou, M. (2020). Cognitive Restructuring vs. Defusion: Impact on craving, healthy and unhealthy food intake. Eating Behaviors, 37, 101385. https://doi.org/10.1016/j.eatbeh.2020.101 385

Kim, B. O., \& Cho, S. (2015). Psychometric properties of a Korean version of the Cognitive Fusion Questionnaire. Social Behavior and Personality: An International Journal, 43, 1715-1723. https://doi.org/10.2224/sbp.2015.43.10.17 15

Kishita, N., Muto, T., Ohtsuki, T., \& BarnesHolmes, D. (2014). Measuring the effect of cognitive defusion using the Implicit Relational Assessment Procedure: An experimental analysis with a highly socially anxious sample. Journal of Contextual Behavioral Science, 3, 8-15. https://doi.org/10.1016/j.jcbs.2013.12.001

Krafft, J., Twohig, M. P., \& Levin, M. E. (2020). A randomized trial of acceptance and commitment therapy and traditional cognitive-behavioral therapy self-help books for social anxiety. Cognitive Therapy and Research, 44. 954-966. https://doi.org/10.1007/s10608-02010114-3 
Larsson, A., Hooper, N., Osborne, L. A., Bennett, P., \& McHugh, L. (2016). Using brief cognitive restructuring and cognitive defusion techniques to cope with negative thoughts. Behavior Modification, 40, 452 482.

https://doi.org/10.1177/014544551562148 8

Lejuez, C. W., Kahler, C. W., \& Brown, R. A. (2003). A modified computer version of the Paced Auditory Serial Addition Task (PASAT) as a laboratory-based stressor. The Behavior Therapist, 26, 290-293.

Levin, M. E., Haeger, J., An, W., \& Twohig, M. P. (2018). Comparing cognitive defusion and cognitive restructuring delivered through a mobile app for individuals high in self-criticism. Cognitive Therapy and Research, 42, 844-855. https://doi.org/10.1007/s10608-018-99443

Levin, M. E., Krafft, J., \& Twohig, M. P. (2020). Examining processes of change in an online acceptance and commitment therapy dismantling trial with distressed college students. Journal of Contextual Behavioral Science, 17. 10-16. https://doi.org/10.1016/j.jcbs.2020.05.001

Lin, Y. Y., Rogge, R. D., \& Swanson, D. P. (2020). Cross-cultural flexibility: Validation of the traditional Mandarin, simplified Mandarin, and Japanese translations of the Multidimensional Psychological Flexibility Inventory. Journal of Contextual Behavioral Science, 15 , 73-84. https://doi.org/10.1016/j.jcbs.2019.11.008

López, J. C. (2016). Experimental analysis of defusion and its impact on performance. Doctoral dissertation, Universidad de Almería.

López-López, J. C., \& Luciano, C. (2017). An experimental analysis of defusion interactions based on deictic and hierarchical framings and their impact on cognitive performance. The Psychological Record, 67, 485-497. https://doi.org/10.1007/s40732-017-02503

Luciano, C., Ruiz, F. J., Torres, R. M. V., Martín, V. S., Martínez, O. G., \& López, J. C. L. (2011). A relational frame analysis of defusion interactions in acceptance and commitment therapy. A preliminary and quasi-experimental study with at-risk adolescents. International Journal of Psychology and Psychological Therapy, 11, 165-182.

Luciano, C., Valdivia-Salas, S., Cabello, F., \& Hernandez, M. (2009). Developing selfdirected rules. In R. A. Rehfeldt, \& Y. Barnes-Holmes (Ed.), Derived relational responding. Applications for learners with autism and other developmental disabilities (pp. 335-352). Oakland: Context Press

Luciano, C., Valdivia-Salas, S., Ruiz, F. J., Rodríguez-Valverde, M., Barnes-Holmes, D., Dougher, M. J., ... \& GutierrezMartínez, O. (2014). Effects of an acceptance/defusion intervention on experimentally induced generalized avoidance: A laboratory demonstration. Journal of the Experimental Analysis of Behavior, 101, 94-111. https://doi.org/10.1002/jeab.68

Luoma, J. B., Hayes, S. C., \& Walser, R. D. (2007). Learning ACT: An acceptance \& commitment therapy skills-training manual for therapists. Oakland, CA: New Harbinger.

Mandavia, A., Masuda, A., Moore, M., Mendoza, H., Donati, M. R., \& Cohen, L. L. (2015). The application of a cognitive defusion technique to negative body image thoughts: A preliminary analogue investigation. Journal of Contextual 
Behavioral Science, 4, 86-95. https://doi.org/10.1016/j.jcbs.2015.02.003

Masuda, A., Feinstein, A. B., Wendell, J. W., \& Sheehan, S. T. (2010). Cognitive defusion versus thought distraction: A clinical rationale, training, and experiential exercise in altering psychological impacts of negative self-referential thoughts. Behavior Modification, 34, 520-538. https://doi.org/10.1177/014544551037963 $\underline{2}$

Masuda, A., Hayes, S. C., Sackett, C. F., \& Twohig, M. P. (2004). Cognitive defusion and self-relevant negative thoughts: Examining the impact of a ninety year old technique. Behaviour Research and Therapy, 42, 477-485. https://doi.org/10.1016/j.brat.2003.10.008

Masuda, A., Hayes, S. C., Twohig, M. P., Drossel, C., Lillis, J., \& Washio, Y. (2009). A parametric study of cognitive defusion and the believability and discomfort of negative self-relevant thoughts. Behavior Modification, 33, 250-262. https://doi.org/10.1177/014544550832625 9

Masuda, A., Twohig, M. P., Stormo, A. R., Feinstein, A. B., Chou, Y. Y., \& Wendell, J. W. (2010). The effects of cognitive defusion and thought distraction on emotional discomfort and believability of negative self-referential thoughts. Journal of Behavior Therapy and Experimental Psychiatry, $\quad 41, \quad 11-17$. https://doi.org/10.1016/j.jbtep.2009.08.00 6

McEnteggart, C., Barnes-Holmes, Y., Hussey, I., \& Barnes-Holmes, D. (2015). The ties between a basic science of language and cognition and clinical applications. Current Opinion in Psychology, 2, 56-59.

McMullen, J., Barnes-Holmes, D., BarnesHolmes, Y., Stewart, I., Luciano, C., \& Cochrane, A. (2008). Acceptance versus distraction: Brief instructions, metaphors and exercises in increasing tolerance for self-delivered electric shocks. Behaviour Research and Therapy, 46, 122-129.

Melo, D., Oliveira, S., \& Ferreira, C. (2019). The link between external and internal shame and binge eating: the mediating role of body image-related shame and cognitive fusion. Eating and Weight DisordersStudies on Anorexia, Bulimia and Obesity, 1-8. https://doi.org/10.1007/s40519-01900811-8

Moffitt, R., Brinkworth, G., Noakes, M., \& Mohr, P. (2012). A comparison of cognitive restructuring and cognitive defusion as strategies for resisting a craved food. Psychology \& Health, 27, 74-90. https://doi.org/10.1080/08870446.2012.69 4436

Mohammadipour, M., \& Ardehaee, F. N. (2016). A psychometric indices of the Farsi Version of the Believability of Anxious Feelings and Thoughts Questionnaire (BAFT). International Journal of Mental Health and Addiction, 14, 752-760. https://doi.org/10.1007/s11469-015-96244

Morin, L., Grégoire, S., \& Lachance, L. (2020). Processes of change within acceptance and commitment therapy for university students: Preliminary evidence from a randomized controlled trial. Journal of American College Health, 1-10. https://doi.org/10.1080/07448481.2019.17 05828

Muris, P., Meesters, C., Herings, A., Jansen, M., Vossen, C., \& Kersten, P. (2017). Inflexible youngsters: Psychological and Psychopathological Correlates of the Avoidance and Fusion Questionnaire for youths in nonclinical Dutch adolescents. Mindfulness, $\quad 8, \quad$ 1381-1392. https://doi.org/10.1007/s12671-017-07141 
O'Loughlin, C. M., Bennett, D. S., \& O'Hayer, C. V. (2020). The nomological network of cognitive fusion among people living with HIV: Associations with rumination, shame, and depressive symptoms. Journal of Contextual Behavioral Science, 15, 245-252.

Oppo, A., Prevedini, A. B., Dell'Orco, F., Dordoni, P., Presti, G., Gillanders, D. T., \& Moderato, P. (2019). Fusione e Defusione. Adattamento e proprietà psicometriche della versione italiana del Cognitive Fusion Questionnaire (I-CFQ). Psicoterapia Cognitiva e Comportamentale, 25. 53-73

Østergaard, T., Lundgren, T., Zettle, R. D., Landrø, N. I., \& Haaland, V. Ø. (2020). Psychological flexibility in depression relapse prevention: Processes of change and positive mental health in group-based ACT for residual symptoms. Frontiers in Psychology, 11, e528. https://doi.org/10.3389/fpsyg.2020.00528

Özkan, S., Zale, E. L., Ring, D., \& Vranceanu, A. M. (2017). Associations between pain catastrophizing and cognitive fusion in relation to pain and upper extremity function among hand and upper extremity surgery patients. Annals of Behavioral Medicine, 51, 547-554. https://doi.org/10.1007/s12160-017-98771

Pinto-Gouveia, J., Dinis, A., Gregório, S., \& Pinto, A. M. (2020). Concurrent effects of different psychological processes in the prediction of depressive symptoms-the role of cognitive fusion. Current Psychology, 39, 528-539. https://doi.org/10.1007/s12144-017-97675

Prudenzi, A., Rooney, B., Presti, G., Lombardo, M., Lombardo, D., Messina, C., \& McHugh, L. (2019). Testing the effectiveness of virtual reality as a defusion technique for coping with unwanted thoughts. Virtual Reality, 23, 179-185. https://doi.org/10.1007/s10055018-0372-1

Ritzert, T. R., Forsyth, J. P., Berghoff, C. R., Barnes-Holmes, D., \& Nicholson, E. (2015). The impact of a cognitive defusion intervention on behavioral and psychological flexibility: An experimental evaluation in a spider fearful nonclinical sample. Journal of Contextual Behavioral Science, $\quad 4, \quad 112-120$. https://doi.org/10.1016/j.jcbs.2015.04.001

Rolffs, J. L., Rogge, R. D., \& Wilson, K. G. (2016). Disentangling components of flexibility via the hexaflex model: Development and validation of the Multidimensional Psychological Flexibility Inventory (MPFI). Assessment, 25 , 458-482. https://doi.org/10.1177/107319111664590 5

Ruiz, F. J., Luciano, C., Flórez, C. L., SuárezFalcón, J. C., \& Cardona-Betancourt, V. (2020). A multiple-baseline evaluation of RNT-focused acceptance and commitment therapy for comorbid generalized anxiety disorder and depression. Frontiers in Psychology, 11, 356.

Ruiz, F. J., \& Odriozola-González, P. (2017). A longitudinal comparison of metacognitive therapy and acceptance and commitment therapy models of anxiety disorders. Anales de Psicología, 33, 7-17.

Ruiz, F., Odriozola-González, P., \& SuárezFalcón, J. (2014). The Spanish version of the Believability of Anxious Feelings and Thoughts Questionnaire. Psicothema, 26, 308-313.

http://dx.doi.org/10.7334/psicothema2013 .221

Ruiz, F. J., Peña-Vargas, A., Ramírez, E. S., Suárez-Falcón, J. C., García-Martín, M. B., García-Beltrán, D. M., Henao, A. M., 
Monroy-Cifuentes, A., \& Sánchez, P. D. (2020). Efficacy of a two-session repetitive negative thinking-focused acceptance and commitment therapy (ACT) protocol for depression and generalized anxiety disorder: A randomized waitlist control trial. Psychotherapy, 57, 444-456.

Ruiz, F. J., \& Perete, L. (2015). Application of a relational frame theory account of psychological flexibility in young children. Psicothema, 27, 114-119.

Ruiz, F. J., Riaño-Hernández, D., Suárez-Falcón, J. C., \& Luciano, C. (2016). Effect of a one-session ACT protocol in disrupting repetitive negative thinking. International Journal of Psychology and Psychological Therapy, 16, 213-233.

Ruiz, F. J., Suárez-Falcón, J. C., Flórez, C. L., Odriozola-González, P., Tovar, D., LópezGonzález, S., \& Baeza-Martín, R. (2019). Validity of the Satisfaction with Life Scale in Colombia and factorial equivalence with Spanish data. Revista Latinoamericana de Psicología, 51, 58-65. http://dx.doi.org/10.14349/rlp.2019.v51.n 2.1

Ruiz, F. J., Suárez-Falcón, J. C., RiañoHernández, D., \& Gillanders, D. (2017). Psychometric properties of the Cognitive Fusion Questionnaire in Colombia. Revista Latinoamericana de Psicología, 49, 8087.

http://dx.doi.org/10.1016/j.rlp.2016.09.00 6

Russell, L. H., Bardeen, J. R., Clayson, K. A., Dolan, S. L., \& Fergus, T. A. (2020). The closed response style and posttraumatic stress: Examining the interaction between experiential avoidance and cognitive fusion among women experiencing sexual trauma. Psychological Trauma: Theory, Research, Practice, and Policy, 12, 627634. https://doi.org/10.1037/tra0000580
Salazar, D. M., Ruiz, F. J., Suárez-Falcón, J. C., Barreto-Zambrano, M. L., Gómez-Barreto, M. P., \& Flórez, C. L. (2019). Psychometric properties of the Avoidance and Fusion Questionnaire-Youth in Colombia. Journal of Contextual Behavioral Science, 12, 305-313. https://doi.org/10.1016/j.jcbs.2018.11.008

Scardera, S., Sacco, S., Di Sante, J., \& Booij, L. (2020). Body image-related cognitive fusion and disordered eating: the role of self-compassion and sad mood. Eating and Weight Disorders-Studies on Anorexia, Bulimia and Obesity, 1-8. https://doi.org/10.1007/s40519-02000868-w

Schumacher, S., Kemps, E., \& Tiggemann, M. (2017). Acceptance-and imagery-based strategies can reduce chocolate cravings: A test of the elaborated-intrusion theory of desire. Appetite, 113, 63-70. https://doi.org/10.1016/j.appet.2017.02.01 2

Schumacher, S., Kemps, E., \& Tiggemann, M. (2018). Cognitive defusion and guided imagery tasks reduce naturalistic food cravings and consumption: A field study. Appetite, $\quad$ 127, 393-399. https://doi.org/10.1016/j.appet.2018.05.01 8

Schweiger, M., Ristallo, A., Oppo, A., Pergolizzi, F., Presti, G., \& Moderato, P. (2017). Ragazzi in lotta con emozioni e pensieri: la validazione della versione italiana dell'Avoidance and Fusion Questionnaire for Youth (I-AFQ-Y). Psicoterapia Cognitiva e Comportamentale, 23, 141162.

Seidler, D., Stone, B., Clark, B. E., Koran, J., \& Drake, C. E. (2020). Evaluating the factor structure of the Multidimensional Psychological Flexibility Inventory: An independent replication and extension. Journal of Contextual Behavioral Science, 
17.

$23-31$

https://doi.org/10.1016/j.jcbs.2020.04.007

Solé, E., Racine, M., Castarlenas, E., de la Vega,

R., Tomé-Pires, C., Jensen, M., \& Miró, J. (2015). The Psychometric Properties of the Cognitive Fusion Questionnaire in Adolescents. European Journal of Psychological Assessment, 32, 181-186. https://doi.org/10.1027/10155759/a000244

Soler, J., Franquesa, A., Feliu-Soler, A., Cebolla, A., García-Campayo, J., Tejedor, R., Demarzo, M., Baños, R., Pascual, J. C., \& Portella, M. J. (2014). Assessing decentering: Validation, psychometric properties, and clinical usefulness of the Experiences Questionnaire in a Spanish sample. Behavior Therapy, 45, 863-871. https://doi.org/10.1016/j.beth.2014.05.004

Sood, M., \& Newman-Taylor, K. (2020). Cognitive fusion mediates the impact of attachment imagery on paranoia and anxiety. Cognitive Therapy and Research, 1-12. https://doi.org/10.1007/s10608-02010127-y

Stroop, J. R. (1935). Studies of interference in serial verbal reactions. Journal of Experimental Psychology, 18, 643-662.

Titchener, E. B. (1910). A text-book of psychology. New York: MacMillan.

Törneke, N., Luciano, C., Barnes-Holmes, Y., \& Bond, F. W. (2016). RFT for Clinical Practice. In R. D. Zettle, S. C. Hayes, D. Barnes-Holmes, \& A. Biglan (Eds.), The Wiley Handbook of Contextual Behavioral Science (pp. 254-272). New York: Wiley.

Trindade, I. A., Barbosa, R., Ferreira, C., \& Pinto-Gouveia, J. (2020). Further validation of the cognitive fusion questionnaire-chronic illness (CFQ-CI) in different health condition samples. Journal of Contextual Behavioral Science. 45-48. https://doi.org/10.1016/j.jcbs.2020.03.004
Trindade, I. A., \& Ferreira, C. (2015). Falling in the traps of your thoughts: The impact of body image-related cognitive fusion on inflexible eating. Eating Behaviors, 19, 49-52.

https://doi.org/10.1016/j.eatbeh.2015.06.0 04

Trindade, I. A., Marta-Simões, J., Ferreira, C., \& Pinto-Gouveia, J. (2018). Chronic illnessrelated cognitive fusion explains the impact of body dissatisfaction and shame on depression symptoms in breast cancer patients. Clinical Psychology \& Psychotherapy, 25, 886-893. https://doi.org/10.1002/cpp.2323

Trindade, I. A., Ferreira, C., \& Pinto-Gouveia, J. (2018). Assessment of chronic illnessrelated cognitive fusion: Preliminary development and validation of a new scale with an IBD sample. Journal of Clinical Psychology in Medical Settings, 25, 356366. https://doi.org/10.1007/s10880-0179536-5

Tyndall, I., Papworth, R., Roche, B., \& Bennett, M. (2017). Differential effects of wordrepetition rate on cognitive defusion of believability and discomfort of negative self-referential thoughts postintervention and at one-month follow-up. The Psychological Record, 67, 377-386. https://doi.org/10.1007/s40732-017-02272

Valdivia-Salas, S., Martín-Albo, J., Zaldivar, P., Lombas, A. S., \& Jiménez, T. I. (2017). Spanish validation of the Avoidance and Fusion Questionnaire for Youth (AFQ-Y). Assessment, 24, 919-931. https://doi.org/10.1177/107319111663233 8

Vilardaga, R., Hayes, S. C., Levin, M. E., \& Muto, T. (2009). Creating a strategy for progress: A contextual behavioral science approach. The Behavior Analyst, 32, 105133. 
Viskovich, S., \& Pakenham, K. I. (2020). Randomized controlled trial of a webbased Acceptance and Commitment Therapy (ACT) program to promote mental health in university students. Journal of Clinical Psychology, 76, 929951. https://doi.org/10.1002/jclp.22848

Wilson, K. G. (2009). Mindfulness for two: An acceptance and commitment therapy approach to mindfulness in psychotherapy. Oakland, CA: New Harbinger.

Wilson, K. G., \& Luciano, M. C. (2002). Terapia de aceptación y compromiso. Un tratamiento conductual orientado a los valores. Madrid: Pirámide.

Yovel, I., Mor, N., \& Shakarov, H. (2014). Examination of the core cognitive components of cognitive behavioral therapy and acceptance and commitment therapy: An analogue investigation.
Behavior Therapy, 45, 482-494. https://doi.org/10.1016/j.beth.2014.02.007 Zhang, C. Q., Chung, P. K., Si, G., \& Gucciardi, D. F. (2016). Measuring decentering as a unidimensional construct: The development and initial validation of the Decentering Scale for Sport. Psychology of Sport and Exercise, 24, 147-158. https://doi.org/10.1016/j.psychsport.2016. 02.006

Zucchelli, F., White, P., \& Williamson, H. (2020). Experiential avoidance and cognitive fusion mediate the relationship between body evaluation and unhelpful body image coping strategies in individuals with visible differences. Body Image, $\quad 32, \quad 121-127$. https://doi.org/10.1016/j.bodyim.2019.12. 002 
Cognitive defusion 27 